\title{
A successful transcatheter aortic valve implantation in an extremely tortuous S-shaped aorta due to chest deformation
}

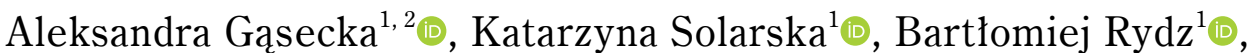 \\ Iga Ślesicka ${ }^{1}\left[\right.$, Bartosz Rymuza ${ }^{1}$, Zenon Huczek ${ }^{1} \oplus$, Janusz Kochman ${ }^{1}{ }^{\oplus}$ \\ ${ }^{1} 1^{\text {st }}$ Chair and Department of Cardiology, Medical University of Warsaw, Poland \\ ${ }^{2}$ Department of Cardiology, University Medical Center Utrecht, The Netherlands
}

A 65-year-old woman was admitted to the hospital for interventional treatment of aortic stenosis. Echocardiography confirmed severe aortic stenosis and a normal left ventricular ejection fraction (60\%). Computed tomography demonstrated an extremely tortuous, S-shaped descending aorta and a significant scoliosis with chest wall deformation (Figs. 1A, B). Considering the complex anatomy, the Heart Team qualified the patient for transcatheter aortic valve implantation (TAVI), despite the low peri-operative risk (1.54\% in the EuroScore II).

Transcatheter aortic valve implantation was performed in a standard manner, under local anesthesia, from the right femoral artery. Once the Confida Brecker Curve guidewire was placed in the aortic arch, the valve was predilated with $20 \mathrm{~mm}$ balloon. A $26 \mathrm{~mm}$ Evolut PRO valve (Medtronic Inc., Minneapolis, Minnesota) was slowly advanced into the aorta, which was techni- cally challenging (Fig. 1C, Suppl. Video 1). The valve was correctly aligned and deployed under rapid pacing $(120 / \mathrm{min})$. Aortogram at the end of the procedure showed no evidence of aortic injury or paravalvular leak (Fig. 1D). Procedural success was confirmed by control transthoracic echocardiography.

The indications for transfemoral TAVI are expanding. The final decision considering the type of procedure should be made by the Heart Team, based on an individual's evaluation. Despite the low risk of mortality following surgery, the patient suffered from the extreme chest wall deformation which made successful sternotomy and latter rehabilitation improbable. Given the flexibility of second generation TAVI delivery systems, it is possible to safely perform the procedure even in a severely tortuous anatomy, which was initially considered a contraindication for TAVI.

Conflict of interest: None declared

Address for correspondence: Janusz Kochman, MD, PhD, $1^{\text {st }}$ Chair and Department of Cardiology, Medical University of Warsaw, ul. Banacha 1a, 02-097 Warszawa, Poland, tel: + 4822599 19 51, fax: + 4822 599-19-57, e-mail: jkochman@wum.edu.pl

Received: 1.03.2021 Accepted: 6.06.2021

This article is available in open access under Creative Common Attribution-Non-Commercial-No Derivatives 4.0 International (CC BY-NC-ND 4.0) license, allowing to download articles and share them with others as long as they credit the authors and the publisher, but without permission to change them in any way or use them commercially. 

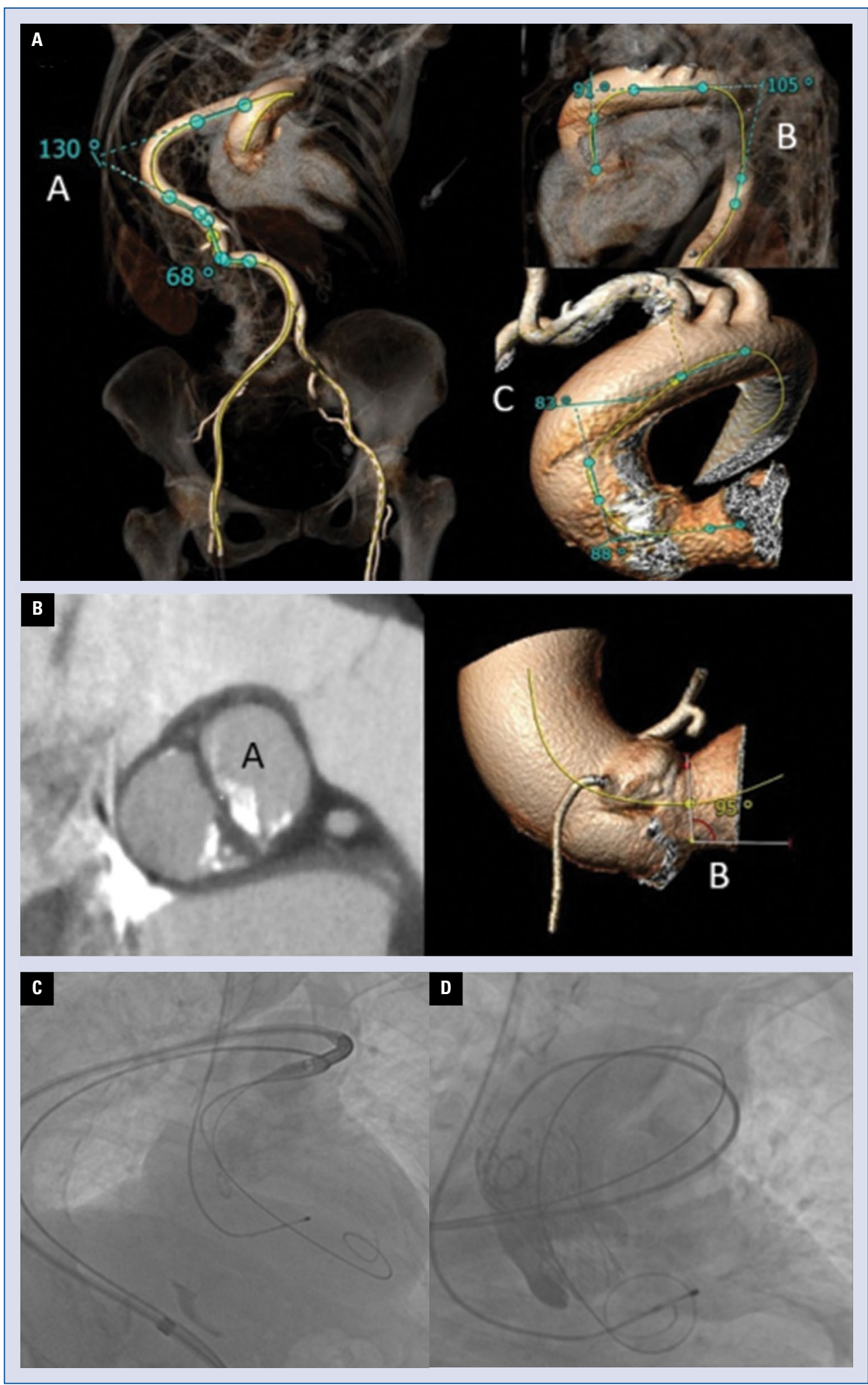

Figure 1. A. Preprocedural multi-slice computer tomography. Three-dimensional reconstruction of access arteries. Severe angulation in descending aorta $(A)$, aortic arch $(B)$ and ascending aorta $(C)$; B. Preprocedural multi-slice computer tomography. Bicuspid anatomy type $0(A)$, with severely horizontal aorta $(B) ; C$. Fluoroscopy images demonstrating advancement of a $26 \mathrm{~mm}$ Evolut PRO valve (Medtronic Inc., Minneapolis, Minnesota) along the tortuous path of the aorta; D. Fluoroscopy image demonstrating the correct position of $26 \mathrm{~mm}$ Evolut PRO valve (Medtronic Inc., Minneapolis, Minnesota) with no evidence of aortic injury or paravalvular leak. 